\title{
Deliberate termination of life of newborns with spina bifida, a critical reappraisal
}

\author{
T. H. Rob de Jong
}

Received: 2 April 2007 / Published online: 10 October 2007

(C) Springer-Verlag 2007

\begin{abstract}
Objects Deliberate termination of life of newborns (involuntary euthanasia) with meningomyelocele (MMC) is practiced openly only in the Netherlands. 'Unbearable and hopeless suffering' is the single most cited criterion for this termination, together with the notion that 'there are no other proper medical means to alleviate this suffering'. In this paper, both (and other) statements are questioned, also by putting them in a broader perspective.

Methods First, a historical overview of the treatment of newborns with MMC is presented, concentrating on the question of selection for treatment. Second, a thorough analysis is made of the criteria used for life termination. Third, a case of a newborn with a very severe MMC is presented as a 'reference case'.

Conclusion 'Unbearable and hopeless suffering' cannot be applied to newborns with MMC. They are not 'terminally ill' and do have 'prospects of a future'. In these end-of-life decisions, 'quality of life judgments' should not be applied. When such a newborn is not treated, modern palliative care always will suffice in eliminating possible discomfort. There is no reason whatsoever for active life-termination of these newborns.
\end{abstract}

Commentaries on this paper are available at doi:10.1007/s00381007-0479-2, doi:10.1007/s00381-007-0480-9, doi:10.1007/ s00381-007-0481-8, doi:10.1007/s00381-007-0482-7, doi:10.1007/ s00381-007-0483-6, doi:10.1007/s00381-007-0484-5, doi:10.1007/s00381-007-0485-4, doi:10.1007/s00381-007-0486-3, doi:10.1007/s00381-007-0487-2, doi:10.1007/s00381-007-0488-1, doi:10.1007/s00381-007-0489-0, and doi:10.1007/s00381-0070490-7.

T. H. R. de Jong $(\bowtie)$

Sophia Children's Hospital, Erasmus Medical Centre, P.O.Box 2060,

3000 CB Rotterdam, The Netherlands

e-mail: t.h.r.dejong@erasmusmc.nl
Keywords Meningomyelocele · Newborn · Suffering · Pain - Quality of life - Termination of life - Palliative care . Groningen Protocol

“An infant with spina bifida cannot 'suffer unbearably'. Infants might be able to experience unbearable pain, but spina bifida does not cause it." (Chervenak 2006)

\section{Introduction and historical overview of the treatment of newborns with MMC}

Before the 1960s, most newborns with meningomyelocele (MMC) were not treated given the consideration that it was in the best interests of the child and family, in most cases resulting in the death of the child. They died from sepsis, meningitis, hydrocephalus, or renal failure. Contraindications to operation included "hydrocephalus, irreparable deformities, paralysis of the sphincters, complete paraplegia or any ulcerative process in the region of the spina bifida" [22]. The influence of the surgical approaches since the 1960s allowed gradually effective early treatment of the complicating hydrocephalus, resulting in many patients surviving into childhood. Early treatment of the spinal lesion and hydrocephalus resulted in decreased mortality and morbidity [66]. 'Wait and see' changed into active treatment. Lorber (1971) published the first large series of patients treated between 1959 and 1969 [44]. He found that only $7 \%$ of the survivors had less than "crippling disability", "most had a quality of life inconsistent with selfrespect, learning capacity, happiness, and even marriage". To "spare children and families prolonged suffering" he proposed the well-known 'Lorber selection criteria'. These four major adverse criteria are: severe paraplegia, gross 
enlargement of the head, severe kyphosis or scoliosis and associated gross congenital anomalies (such as heart disease) or major birth injuries. No active treatment was advised for children who had one or any combination of these criteria. The result of this proposed selection was to treat only those with lesions on lumbar and sacral level without any other major complication. Others would, according to Lorber, "die quickly".

Since the Lorber era there have been tremendous successes in the treatment of patients with MMC [48, 50]. Over the last 30 years, continual progress has not only been made in the neurosurgical (closure of the back defect, shunting, or endoscopic techniques for the complicating hydrocephalus, treatment of tethered spinal cord and Chiari II malformation), orthopedic (treatment of scoliosis, correction of club feet), urological (preserving normal renal function, securing social continence), and psychosocial treatment of patients with $\mathrm{MMC}$, but also in support for independence by modern rehabilitation programs.

Nevertheless, early decision making (for restriction) and selective treatment of newborns with MMC is still propagated [27, 69], resulting in approvals but also in critiques $[7,23,41,42,49,79]$.

What is considered ethical at one time, or in one country, can be considered unethical or unacceptable at/in another. The ethical debate on treating children with $\mathrm{MMC}$ is unique in the sense that these children will/can have a life of substantial and sometimes severe physical disability but often with normal mentation, this in contrast to severely psycho-motor handicapped children. Children and adults with MMC can be aware of their deficits.

Lorber (1971) stated that untreated children will die quickly [44]. However, he delivered the children anticonvulsants to prevent seizures, opioids and chloral hydrate to prevent pain [25]. One pediatrician has said that these untreated children received the same care and attention as others, being fed and loved, but they also received $60 \mathrm{mg} /$ $\mathrm{kg}$ body weight of chloral hydrate, four times a day. This was being administered for pain, but the children who were operated on did not receive this regimen. Another physician just said: we don't feed them [79]. Consequently, the duration of life seems to depend on the attitude of the responsible doctor.

In the United States, untreated children were not given morphine or anticonvulsant drugs and were fed every $4 \mathrm{~h}$, resulting in many 'survivors' with severe handicaps. On the contrary, in the United Kingdom the children died quickly. However, the question remains if these children were really in pain or suffered from seizures; perhaps not.

Not all physicians did follow the 'Lorber criteria', but treated all children unselectively, regardless of the level of the lesion. This approach resulted in multidisciplinary MMC clinics and MMC teams. The nonselective treatment of newborns with MMC started in the early 1970s and gives us a picture of long-term outcome of newborns with MMC $[4,9,32,48,52]$ and also of the quality of life and health status of adults with spina bifida [58, 63]. Some physicians became bitter after treating children with MMC for years [2].

In the early 1980s, the 'Baby Jane Doe ('Stony Brook baby') case resulted in the United States in an ethical debate on the prospect physicians make about the future life of handicapped children born with MMC. This girl was born with MMC, complicated with hydrocephalus (although diagnosed by the attending physician as microcephalic). The team of physicians told the parents that the child would spend her life "lying in bed, bottle fed....She would experience no joy, sadness or any such emotion except response to pain and would develop no cognitive skills. She might survive for 20 years" [51].

Based on the given information, the parents agreed not to treat their child. However, the physicians turned out to be wrong. Although the child developed meningitis, sepsis, and hydrocephalus (which were only treated to some extent), she survived all these complications, was taken home, became ambulating and communicating on an acceptable level of intelligence, all this despite the partial treatment [24, 25].

After the introduction of alpha feto-protein (AFP) screening in the late 1980s (followed by amniocentesis) and ultrasound diagnosis, many fetus with MMC can now be detected early in pregnancy. Nowadays, after being counseled, most pregnant couples decide to abort a fetus with MMC (in many Western countries resulting in an abortion rate of $95 \%$, resulting in fewer children with MMC born $[13,14,53])$, seen by many as 'prevention' of MMC. But what advice should neonatologists, neurologists, or neurosurgeons give the parents when a full-term child with MMC is born? Is the advice not to treat, or to terminate the life of the newborn deliberately (involuntary euthanasia) an ethically defendable one?

Deliberate and active termination of life in newborns with MMC is only discussed and practiced in an open way in the Netherlands [35, 38_40,71_76, 78]. The judgment "unbearable and hopeless suffering" of the newborn and "the prospect of unbearable and hopeless suffering" in the future, together with the notion that there is "no other proper medical means to alleviate the unbearable suffering" form the basis for this decision [73]. Because these judgments are questioned, and to quantify the level of discomfort in these neonates, the "Rotterdam Prospective Study on Discomfort in Newborns with Spina Bifida" was started in 2005 in the Erasmus Medical Center (EMC)Sophia Children's Hospital (Rotterdam, the Netherlands). Although in due time the results of this study will be published, some important aspects will already be addressed in 
this paper by elaborating on the case of a newborn with a very severe form of MMC and hydrocephalus.

\section{Deliberate termination of life in newborns with MMC in The Netherlands}

The Dutch neurosurgeon De Lange analyzed the selection criteria for treatment of newborns with MMC in the Netherlands already in the 1970s [41, 42]. It became clear from an enquiry among Dutch neurosurgeons that a number of them advised against treatment on the basis of physical handicaps alone. Others regarded the expected mental abilities as an overruling factor. When basic communication skills could be expected, most children were treated. At the time, deliberate termination of life was never practiced. De Lange (1970) also concluded "If we were to decide that in our opinion patients with spina bifida who are below a certain level of physical or mental ability should not be kept alive, it should be illogical not to apply the same rules to other categories of handicap." [41]

In the 1980s, the Dutch ethicist Hertogh (1988) published his paper "Ethical considerations on the dilemmas caused by the selective treatment of newborns with MMC" in the leading Dutch medical Journal [30]. He elaborated on the philosophical and ethical aspects of the Lorber selection criteria: "The objective medical fact of a physical shortcoming is something completely different than the subjective reality of 'being-handicapped' itself. Studies have shown that living as 'being-handicapped' does not correlate directly to the severity of physical shortcomings. The question as to what can be considered as an acceptable handicap transgresses, in other words, the scope of what can be ascertained in a medical-scientific way and this, therefore, refers inevitably to the subjective experience. It has to be questioned whether the quantification of qualitative aspects of medical treatment perhaps offers nothing more than pretence-rationality, caused by the used decisive terminology. In conclusion: up to date the criterion 'quality of life' appears to be more deceptive than clarifying in the medical decision about the possible continued existence of a newborn with spina bifida." [30] $\mathrm{He}$ also referred to the ethics of the philosopher Levinas: "Ethos cannot be founded in scientific facts; it is founded in the human relationship itself. Mutual dependency, which is characteristic for 'human being', makes us responsible just by itself and therefore defines 'the disposition of ethos' as a rational fact. This relationship always precedes facts themselves."[30] In other words: human beings, just because of the fact that they are human beings, have an intrinsic and mutual responsibility for the well-being of others, this responsibility itself preceding physical qualities.
This thoughtful paper, however, was not given much attention in the Dutch medical press.

In 1993, baby Rianne was born in a small town in the Netherlands with a MMC at level of the first and second lumbar vertebrae complicated by hydrocephalus. The lower limbs were deformed and paralyzed. Computed tomography (CT) scan of the head confirmed the diagnosis of severe hydrocephalus. On the first day of her life, the decision was made by the pediatrician and the gynecologist in consultation with a neurologist, neurosurgeon, and pastor not to operate the back lesion and the hydrocephalus. On the fourth day of her life, at the request of the parents, the gynecologist Prins terminated the life of the baby by a lethal injection. In an interview, Prins stated [37]: "Closing the defect and fighting infections with maximal treatment could enable the child to survive for years. No one knows how long". On the question of what an operation could have accomplished, Prins answered: "The defect would have been closed. The possibility of secondary infection, which was an immediate threat to her life, would have been diminished. Her brain pressure would rise, however, and it would have been necessary to implant a shunt". On the question of how he would calculate the benefit of treatment, he answered: "It (the operation) would have prolonged her life without treating the symptoms and consequences of the defect because the operation would not have alleviated them. The operation would only have minimized the possibility of infection, but it would have created the necessity for repeated operations involving the shunt and the urological system because there were obstructions in the passage between the kidney and the bladder. Her brain damage was so extensive and the possibility of movement so limited. She would never have been able to walk or sit unsupported; she would have been incontinent in her bladder and bowel. There was sensory damage as well; she could not feel sensation in her lower body. She would have started life with repeated operations, need for persistent medical attention, no possibility for self-support, and very low communicative ability" [37]. As a definition of a severe handicap he stated: "This can relate to the estimated possibility of becoming happy" [37], and he further referred to the Dutch Association of Paediatrics who developed criteria, including the lack of capacity to communicate, lack of capacity for self-maintenance, persistent need for medical assistance, and the existence of pain. All these criteria grouped together gave a picture of the baby's quality of life. Because most of the criteria were satisfied, the baby was considered to be severely handicapped, resulting in a very poor expected quality of life; the child was not operated on because of the severity of the expected handicaps.

On the necessity of life-termination, Prins (1997) explained: "The baby was in a great deal of pain and the 
normal analgesics did not work well. So it would have been necessary to use narcotic analgesics - morphine-like drugs. And that would have caused depression of consciousness. It is clear to me that the use of such drugs would have depressed normal functioning-behavior, expressions, and sensibility. Using morphine-like drugs would have caused a situation of floating between heaven and earth. It would have been dishonest and should be considered as unethical and unjust. There is no moral difference between killing and withholding useless medical treatment. There is an emotional difference. And there should not be a legal difference" [37].

Although elements of the offense of murder were proven, the physician was acquitted based on the unavoidable conflict of duties between his duty to prolong life and his duty to alleviate unbearable suffering [26].

In 1996, three Dutch child neurologists and one neurosurgeon questioned in the leading Dutch medical journal the active termination of life of newborns with MMC [59]. They defended the opinion that (severe) handicapped life could also be meaningful. Deliberate termination of life was not considered appropriate; sedation and the delivery of opioids were mandatory in the case of suffering. Not treating a child with MMC should not result in a more severe handicapped life; the decision to withhold treatment was only made in the case of severe pulmonary or cardiac complications with the prospect of early death. The possible suffering of the parents should not be an indication for deliberate termination of the life of a newborn with MMC. They referred to the study of Steinbok et al. (1992) [68] for their argument that the life of children and adults with (severe) MMC can be meaningful [59].

In 2003, the Dutch physician/medical ethicist Van de Vathorst stated that whenever it is decided not to treat a defective newborn, deliberate termination of the life of this newborn should be regarded as a moral demand, based on the principle of 'mercy' [72]. She illustrated her arguments with a case of a newborn with a thoracic MMC. Interestingly enough, the life of this child was not terminated. It died by itself, a few days old, because of pulmonary insufficiency. Although she received a national award for this paper, it resulted in several disapproving letters to the editor.

In January 2005, two pediatricians, one physician, and one pediatric neurologist reported on the deliberate termination of life of 22 newborns in the Netherlands between 1997 and 2004 [73]. Explaining the fact that all 22 cases were newborns with MMC and hydrocephalus, Verhagen et.al. referred to the 'baby Rianne case', stating that "her life was dominated by unbearable suffering" and "since this case it is established that newborns with a severe form of spina bifida do suffer severely" [73].

According to the authors, the deliberate termination of life was necessary because of the presence of "unbearable and hopeless suffering, acutely and long-term, with no other proper medical means of alleviating the suffering" [73]. All parents consented to the proposal of termination of life; in four cases, they explicitly requested for it. For the public prosecutor, the termination of life was acceptable if four requirements were properly fulfilled: (1) the presence of hopeless and unbearable suffering, (2) consent of the parents to termination of life, (3) consultation of another physician or of a multidisciplinary MMC team, and (4) a proper and careful execution of the termination. These four criteria eventually became the cornerstone of the so-called 'Groningen Protocol', a protocol meant to insure that the decision for life termination, the executing itself, together with reporting to the legal authorities, are all conducted in a proper way. This protocol was approved and adopted by the Dutch Association of Paediatrics in 2005.

The motivation for the judgement of 'unbearable and hopeless suffering' in the 22 cases of spina bifida was [73]:

1. 'suffering' (acute and chronic pain, physical pain) $(100 \%$ of the 22 cases);

2. the 'lack on ability to live or do things independently' as the result of 'severely disturbed sensomotoric development' ( $100 \%$ of the 22 cases);

3 . the 'lack of possibility to verbal and non-verbal communication' ( $82 \%$ of the 22 cases);

4. 'the prospect to dependency to the medical circuit as the result of frequent hospital admissions and operations' ( $77 \%$ of the 22 cases)

5. the 'life expectation' ('the burden of severe suffering increases by a longer life span') (in 59\% of the 22 cases).

None of the cases led to prosecution; all cases were found to be in accordance with good medical practice.

This article of Verhagen et al. (2005a) gave rise to only a few reactions in the Netherlands. Kompanje et al. (2005) [38] questioned the validity of 'unbearable suffering' as a useful criterion. They also stated that with the use of modern palliative care, 'suffering' always can be dealt with in an adequate way, as did Laane (2005) [39, 40]. De Jong (2006) [35] made a plea for 'letting them die' instead of 'making them die' in the case of an untreated newborn with MMC.

On request of the editor of the New England Journal of Medicine, Verhagen and Sauer (2005) published another article concerning the Groningen protocol and the 22 cases [75] and a similar article appeared in Pediatrics [76]. The reactions in the international medical press were mostly negative. In his article "Control of suffering on the slippery slope of care" in the Lancet, Feudtner (2005) also addressed the poor quality and the insufficiency of the offered palliative care and questioned whether legalization of active termination of life might not lead to the abuse of it [21]. Saugstad (2005) stated in the Acta Paediatrica: "Neonatologists must be extremely careful not to start on the 
slippery slope ending in the Dutch practice of euthanasia of newborns. I would strongly warn against this attitude, which I find non-compatible with Western humanistic traditions" [61]. Jotkowitz and Glick (2006), in the Journal of Medical Ethics, were worried: "We feel an important line has been crossed if the international medical community consents to the active euthanasia of severely ill infants and are concerned about the extension of the policy to other at risk groups" [36]. Bondi et. al. (2006), in Pediatrics, made a plea for an open discussion: "Rather than performing an in-depth examination of the philosophical, ethical, and moral implications of this protocol, the authors focus on its technical details and acceptability within the European medical community. The Groningen Protocol centers not on patient self-determination, but instead on the perception of the patient's current and future suffering. Although the authors note that an open discussion of these issues is "extremely important," they fail to initiate it. We hope that thoughtful ethicists and legislators will initiate the open discussion that the authors advocate" [8]. In their article 'Why the Groningen Protocol should be rejected', Chervenak et al. (2006) concluded that: "The justification they offer is woefully inadequate. It relies on appeals to the concepts of "hopeless and unbearable suffering," the "best interests of the patient," and "medical-ethical values," but it never explains these concepts, and it gives no ethical argument for their clinical application. In fact, not only is no argument for the Protocol given, none can hope to succeed. The Groningen Protocol should therefore be rejected as the basis for obstetric and neonatal practice in The Netherlands and throughout the world." (11)

Manninen (2006a), finally, made an important contribution with her article "A case for justified non-voluntary active euthanasia: exploring the ethics of the Groningen Protocol" in the Journal of Medical Ethics [45]. She made a thoughtful plea for the ethics of the Groningen Protocol: "What the Groningen Protocol proposes to do is both ethical and also the most human alternative for these suffering and dying infants." Newborns eligible for this protocol "do face no future at all - that is, the infants must be terminally ill", "will die soon no matter what actions doctors undertake, modern medicine can do nothing to save them", "have no prospects, have crossed the threshold into a comparatively valueless state of existence", "will spend the remainder of their lives in a chronic state of nothing but pain and suffering" [45]. Interestingly enough, on November 23 an additional letter of herself, "Regarding the Groningen Protocol" [46], was published in the same journal. Some key passages of this letter: "It has recently been brought to my attention that the physicians of the Groningen Hospital who originally proposed the Groningen Protocol have proposed to violate the first two conditions of the original Groningen Protocol: (1) The suffering must be so severe that the infant has no prospects for a future; (2) There is no possibility that the infant can be cured or alleviated of her affliction with medication or surgery. For example, Dr. Verhagen has maintained that the Protocol could apply to infants that are not necessarily terminally ill, but nevertheless may face a compromising future. In essence, the Groningen Protocol has begun to make quality of life judgments. If the Groningen physicians have commenced making quality of life judgments, they have strayed away from the original purpose of the Protocol, and this, I believe, may have concerning ethical implications. As I write in my paper: "...the Groningen Protocol does not make quality of life judgments, and it is because of this very important requirement that the Protocol strikes me as humane and morally permissible, for it seems utterly vicious to extend the life of a suffering infant with no prospects for a future. If the infant did have a possible future ahead of her, I would be more hesitant to condone a legal practice that begins to make quality of life judgments, for such judgments can be, and have been, subject to error." [46] In her opinion, in these end-of-life decisions 'quality of life judgments' should not be made and, in a way, with this letter she also highlights the inconsistencies in the reports by Verhagen et al. Being of crucial importance, the subject of 'quality of life judgments' will be discussed more extensively in paragraphs 4 and 5 .

Finally, in 2006, in The Netherlands a national multidisciplinary expert review committee has been appointed. In the case of active termination of the life of a newborn, the responsible physician is supposed to inform this committee, which then has to determine whether the criteria for life termination have been met. Subsequently this committee has to advise the Public Persecutor's Office (OM) whether the physician should be prosecuted or not. Although such a committee seems to guarantee more certainty, it can be doubted, however, if this 'checking on afterhand' is of much value for the newborn in question. It seems to be more sensible to change this procedure to a 'checking on beforehand'. Legally, this might perhaps be difficult to establish, but it seems not justifiable that legal procedures themselves do dominate the question of appropriateness of life termination; errors in judgment being unacceptable (cf. the level of certainty required for a death penalty in crime in, e.g., the USA).

\section{Analysis of the mentioned criteria for non-treatment and deliberate termination of life}

\section{Suffering}

The actual presence of acute unbearable and hopeless suffering of the newborn and the prospect of future/chronic 
unbearable and hopeless suffering as the result of handicaps, pain, and discomfort is the most given argument for deliberate termination of life in neonates with MMC. In the recent Dutch series, this suffering was stated to be present in $100 \%$ of the 22 cases $[73,75,76]$.

Acute pain Not any convincing evidence can be found in the literature that newborns with MMC actually do suffer from untreatable pain in the days after birth caused by their back lesion or by other complications. A pediatric surgeon who devoted much of his professional life of more than 30 years to the treatment of those who have been born with spina bifida stated: "I personally have seen little evidence that the babies have pain in the newborn period, nor have I found them unable to sleep." [79] Delight and Goodall $(1988 ; 1990)[17,18]$ studied the experiences of parents of 44 children born with MMC, all managed without any surgery. All 44 children died before their first birthday. Only a quarter of them did require some medication such as analgesics and anticonvulsants; half of them were given drugs in the dying period. Analgesics were given in a low dose simply to enhance their quality of life $[17,18]$.

Chronic pain The literature on chronic pain in MMC is scarce. The first systematic examinations of the nature and prevalence of pain in children with MMC was published in 2005 [12]. Headache is not uncommon in adults with $\mathrm{MMC}$ and is associated with hydrocephalus. In this series, $56 \%$ of 68 patients reported experiencing pain once a week or more frequent. Of the shunted children, $88 \%$ reported headaches compared to $79 \%$ of the children without a shunt [12]. Children in this study reported frequent and sometimes intense pain at multiple locations associated with the physiological sequelae, equipment usage, and medical management of the disability. The authors concluded that children with spina bifida frequently report clinically significant, under-recognized and untreated pain, and they propagated proper care and adequate medical management of these children. In another series, $55 \%$ of 42 patients underwent investigations for one or more episodes of chronic headache due to shunt malfunction, ventriculostomy failure, or symptomatic Arnold-Chiari malformation [20]. Although all these problems sometimes can be fairly serious, the notion of 'unbearable and hopeless suffering' is never mentioned.

The 'lack of ability to live or do things independently' as the result of 'severely disturbed senso-motoric development'

The second argument for unbearable and hopeless suffering is the prospect of lack of ability to live or do things inde- pendently as the result of severely disturbed senso-motoric development experienced by the patient in childhood, puberty, and adult life [73].

McLone reported in 1982 the results of the unselective treatment of 100 consecutive newborns with MMC [48]. After a follow-up period of 3.5 to 7 years there were 86 survivors. He concluded that the total percentage of children who could be independent and competitive is approaching 70-80\%. Hunt and Oakeshott (2003) [32] and Oakeshott and Hunt (2003) [52] studied the outcome in 117 unselected and actively treated patients with MMC at age 35 . The patients were treated between 1963 and 1971 without any attempt at selection. Forty-two patients had a severe lesion at a sensory level above Th11, 30 of whom died, most before their first birthday. They died mostly of cardiorespiratory or renal failure, hydrocephalus, or CNS infection. Two of the 12 survivors live independently, drive cars, and have an open employment; six have an IQ $>80$. In another study [62], 29\% out of 60 adolescents with spina bifida had the lesion at a high lumbar or thoracic level. The authors studied the quality of life in these patients. They concluded that there were no significant relationships between the level of the lesion or spina bifida severity and the overall quality of life, which appeared to be 70 to 80 on a 100 -point scale; both patients and their parents view the overall quality of life positively [62].

Besides these results, criteria such as 'living independently' or 'doing things independently' can be confusing when deciding about the future life of vital newborns. Most people who do live a meaningful life are dependent on others or interdependent on each other. In fact, interdependency and especially the willingness to care for other (perhaps dependent) people can be considered as a criterion of a truly civilized society, certainly so when this means to offer 'something for nothing' (this being real mercy).

The 'lack of possibility of verbal and non-verbal communication'

In 18 of the 22 studied Dutch cases, it was predicted "(future) communication of and with the child would not be possible, neither verbally nor nonverbally" [73]. In other words, these babies were predicted to be or to become in a state of deep coma or in a persistent vegetative state. Neither of these states of very severe disturbed consciousness, however, is applicable to a newborn with MMC and hydrocephalus. Furthermore, several publications concerning the level of mental functioning of adults with MMC have been published $[3,4,9,32,33,47,67,68,70]$. Intellectual development varies between normal IQ (this being the case in $60 \%[9,68]$ to $70 \%$ [32] of the studied population) and severe mental disability, but the predicted complete absence of the possibility to communicate is never mentioned. On 
the contrary: "Virtually all infants with spina bifida are capable of meaningful human relationships, independent of the level of the lesion. Indeed, most are of normal intelligence" [23]. Aside from this incorrect medical description there are some other important aspects that need to be highlighted. When all communication is claimed to be impossible, one wonders by what methods at all (the amount of) suffering can be established. Furthermore, when a person is in such a state of deep coma or in a persistent vegetative state, there simply is no cognitive experience whatsoever, also not of (unbearable) suffering. This was confirmed in a recent conviction of the Dutch Medical Disciplinary Committee against a general practitioner who euthanized a comatose patient; the ground of the verdict being "because of the comatose state there was no longer any question of unbearable suffering nor any question of euthanasia" [15].

'The prospect of dependency to the medical circuit as the result of frequent hospital admissions and operations'

It seems hardly possible to quantify this criterion in such a way that it can be used to justify life termination of vital newborns. When compared to persons with other congenital malformations or congenital diseases or some acquired diseases, patients with MMC do not appear to need substantially more medical care than, e.g., patients with intracranial tumors or with chronic diseases such as severe pulmonary, cardiac, or neurological disorders. Furthermore, the claim of Verhagen (2004) that "this child would have to undergo at least 60 operations in the course of a year to temporarily alleviate its problems" [71] again cannot be substantiated: a retrospective survey of treated newborns with MMC over 2 years in the Sophia Children Hospital showed that three to four operations were needed in their first year of life.

'Life expectation' ('the burden of severe suffering increases by a longer life span')

It is clear that the longer a patient lives, the more medical care will be needed in a quantitative way. Whether this means that this will affect the experienced quality of life in a negative way remains totally unclear and cannot be predicted. Furthermore, patients with MMC do require relatively much of their medical care in their first two decades, this steadily decreasing when they grow older and when disabilities and coping with these disabilities are gradually stabilized.

Can 'suffering' be applied as a reasonable criterion in newborns?

Suffering, especially the 'unbearable and hopeless' aspects of it, is a complex psychosocial phenomenon and by definition strictly individualized: only the individual itself can experience the existence, the intensity, and hopelessness of it. Others (parents, physicians, nurses) can only to some degree make an estimation of it. It is therefore tentative whether 'suffering' can be applied to newborns at all. What is possible, however, is to establish quite precisely the level of '(dis)comfort' of a newborn by making use of standardized score charts such as the Comfort score and the Visual Analogue Scale (VAS) (see below).

The Dutch physician Beijk(1998) stated it as follows: "suffering will be interpreted by every patient, by every doctor, and by every other involved person in a different way and therefore can lead to completely different conclusions. The bearableness is especially dependent on personal and environmental factors; it is all about the subjective experience of the individual itself who is suffering, about the durableness of the suffering, and about the wish to die" [6]. In 2005, in his Ph.D. thesis, also Hamburg (physician and jurist) concluded "for the criterion 'suffering' there are no objective or scientifically validated criteria available, with the consequence of decisions of lifetermination being dependent of the subjective judgment of the doctor, leading to inconsistent decisions" [29]. Therefore, according to Hamburg, "in a time of evidence-based medicine 'suffering' is not acceptable anymore" [29], as also was suggested by Kompanje et al. (2005) [38]. Although Beijk and Hamburg are referring to the practice of euthanasia (which in the Netherlands is strictly referring to competent patients wishing to die), their statements are the more applicable to newborns, as in these cases predictions are being made about future suffering of others. According to Chervenak et al. (2006): “An infant with spina bifida cannot have and therefore cannot have lost the ability to realize intentions, desires, and hopes for the future; it can feel pain but cannot 'suffer' as a psychosocial phenomenon" [11]. Laane (2005a) came to the same conclusion: "having no biographical consciousness, 'suffering' cannot be applied to newborns [39]. To date, it is unclear why this improper use of 'suffering' still continues in this debate.

\section{Can physicians predict quality of life?}

\section{Counseling the parents}

In a time in which most fetuses with MMC will be detected by AFP and amniocentesis or by ultrasound diagnosis (in most cases being followed by iatrogenic abortion), the birth of a newborn with MMC is increasingly becoming a rare phenomenon [14]. The decision to terminate a pregnancy in the case of a fetus with MMC is usually made shortly after the diagnosis. It can be questioned whether there is enough 
time for proper counseling about the prospect of living with spina bifida, as a patient and also as parents. Freeman (1998) stated: "Decisions are made by the parents without knowledge of the child's future; without knowing whether the child will have minimal deficit and walk with only short leg braces or walk with no braces at all, and without awareness of whether this child will have a thoracic lesion with high paraplegia and spend his or her life in a wheelchair. Few parents at that stage in the pregnancy know much about spina bifida or about what life will be like for that child and for that family. In other words, these rarely are informed decisions" [25]. He points in the same direction concerning physician experience: "Today, few younger physicians have experience with the decisionmaking process for spina bifida either before or after birth. Thus, physician advisors will lack experience with the joys of caring for a child, even a handicapped child, as well as experience with the pains and problems. They will have little experience with the feelings of the handicapped children themselves. With the lack of experience, how should the physician counsel? On what basis can the inexperienced physician advise uninformed parents? What decision should the parents make?" [25]

In their article "Tell the truth about spina bifida," Bruner and Tulipan(2004) also showed their worries about the quality of counseling: "Unfortunately, many healthcare professionals are equally ignorant of the current prognosis of children with spina bifida who have ready access to comprehensive care in a modern multidisciplinary clinic. As a result, much of the information initially provided to couples with a newly diagnosed fetus is biased and misleading. As medical ethicists Bliton and Zaner at Vanderbilt University Medical Center observed, "To date we have met and held intense conversations with more than 150 pregnant women and their partners. Many times, couples admitted, the initial counseling they received from their obstetrician was slanted - both against disability and toward termination of pregnancy. What they remembered was how the initial obstetric consultation portrayed as grim a picture as possible about their future child's prognosis." [10]

The statements of Verhagen et al. (2005) mentioned earlier, together with other incorrect predictions ("these newborns have no prospect of a future and no chance to survive at all; are barely able to breathe", "these children face a life of agonizing pain that cannot be alleviated by any proper medical means", "the child would suffer such unbearable pain that it has to be constantly anaesthetized" [71], that "they all have spina bifida of the most severe form at level of the neck and all have non-functioning kidneys" [78]), unfortunately seem to confirm these worries, also in counseling the parents of a newborn with MMC. To date, it is not clear why such incorrect information is presented to parents, colleagues, and society as a whole. When parents are told that communication with and of their child never will be possible, that their child will face a life of agonizing pain and will suffer unbearably, that this suffering cannot be alleviated by any means, that annually at least 60 operations will be needed to offer some (but only temporary) relief, then these parents are left without any hope and their consent/decision to nontreatment, or to active termination of life, almost can be predicted. However, in such situations the fundamental concept of 'informed decisions' is obviously violated.

Does the level of the lesion matter?

Does the level of the lesion determine the amount and severity of disturbances? In general, the higher up the spine the lesion is, the more likely are severe neurological disabilities to be found. Cervical lesions often do not contain neural tissue and are simple meningoceles. At lower levels (thoracic and especially lumbar), the converse is true: the infant nearly always being (partially) paralyzed below the level of the lesion, the cord showing the classical features of dysplasia [66]. However, the extent of handicaps that a person with MMC experiences is determined not by the site of the lesion, but almost entirely by the neurological deficit. Verhoef (2005) concluded that young adults with a mild form of spina bifida (and subsequently with few disabilities), did experience their disabilities more often as problematic than contemporaries with a serious form of spina bifida [77]. Likewise, in the study of Seller (1990) [65], eight patients ended up with minimal handicaps, having bony lesions in the thoracic (one patient), lumbar (two patients), and lumbosacral (five patients) spine. Three others with lumbosacral bony lesions were among the most gravely handicapped [65]. According to Hetherington (2005), low lesions do not necessarily indicate a mild course; physical well-being was not related to the level of the spinal lesion [31]. Although persons with sacral lesions showed less impairment compared to persons with higher spinal lesions, Padua et al. (2002) did not find a correlation between quality of life (both physical and mental) and the site of the lesion [54]. According to Pit-ten Cate et al. (2002), lesion level, type of spina bifida, and gender were not significantly related to the quality of life in children with spina bifida [55]. This is in agreement with the results of the study of Sawin et al. (2002) [62]: no significant relationship with lesion level, spina bifida severity or shunt status and quality of life was found in 60 adolescents. Schoenmakers (2003) [64] concluded that being independent in mobility contributes more to quality of life than other functional abilities such as whether or not being wheelchair-dependent. And, although children with the most severe forms of MMC have significantly more and severe disabilities than children with milder forms of 
MMC, scores about self-esteem did not differ significantly between the two groups [64].

In conclusion, the level of the lesion does not correlate with the actual experience of the handicaps themselves.

Is the diagnosis 'extensive brain damage' easy to make?

There is little doubt that surgical procedures are unjustified in hydrocephalic newborns with little or no potential for independent survival, the decision as to what constitutes as irreversible and severe brain damage may however be difficult to make. Ventricular size alone cannot be used as a conclusive predictive criterion. It has been repeatedly demonstrated that there is no consistent correlation between the thickness of the cortex and the eventual psychomotor development. Barf et. al. (2003) [3] concluded that cognitive status was especially negatively influenced by multiple shunt revisions and by other pathologies associated with hydrocephalus. Amacher and Wellington (1984) [1] treated 170 children with hydrocephalus in 636 operative procedures and concluded that "there is no difference in results based upon measurement of the initial thickness of the cerebral mantle." They found normal intelligence in $63 \%$ of the 5-year survivors. In a recent study also, Beeker et al. (2006) described the difficulty in making a reliable prognosis of the intellectual development based on ventricular size [5].

\section{'Quality of life', to conclude}

It seems impossible to predict with certainty the future quality of life of newborns with MMC. One also has to be aware of the fact that the self-reported quality of life of children with handicaps does not differ from that of children without disabilities, and health care professionals are known to underestimate disabled persons' quality of life as compared to self-reports [11]. Generally speaking, prognostic judgments about quality of life are conceptually plausible; their failing is simply that, given the available evidence, they do not appear to be reliable [11]. Finally, and perhaps the most important, quality of life judgements are considered as being ethically unacceptable in end-of-life decisions $[45,46]$.

\section{Non-discrimination principle}

In his Ph.D. thesis, Dorscheidt (2006) raises the issue as to whether the deliberate termination of the life of disabled newborns is compatible with the "non-discrimination principle', in particular the legal prohibition of discrimination on the ground of disability [19]. Deliberate termination of the life of newborns with spina bifida is always preceded by a non-treatment decision (as in the baby Doe case and the baby Rianne case) and according to Dorscheidt, the decision of non-treatment should be questioned with regard to the non-discrimination principle as well. He elaborates on two fundamental rights of the child, being the child's right to life and its right to health(care), mentioned in international human rights instruments such as the Universal Declaration of Human Rights (UDHR), The United Nations Convention on the Rights of the Child, and the European Convention of Human Rights, and on the authoritative views of international human rights bodies such as the United Nations Children's Rights Committee (UNCRC) and the Committee on Economic, Social and Cultural Rights (CESCR).

Some examples: Article 25, UDHR: "Everyone has the right to a standard of living adequate for the health and well-being of himself, including medical care and the right to security in the event of disability. All children shall enjoy the same social protection". CESCR, par. 26: According to standard Rules: "States should ensure that persons with disabilities, particularly infants and children, are provided with the same level of medical care within the same system as other members of society." UNCRC: "In its examination of States parties reports, the Committee should commit itself to highlighting the situation of disabled children and the need for concrete measures to ensure recognition of their rights, in particular the right to live, survival and development". UN, General Counsel: "We will take all measures to ensure the full and equal enjoyment of all human rights and fundamental freedoms, including equal access to health, education and recreational services, by children with disabilities and children with special needs, to ensure the recognition of their dignity, to promote their selfreliance and to facilitate their active participation in the community". Proposal text of the American delegacy for the UN Convention to Promote and Protect the Rights and Dignity of Persons with Disabilities: "States Parties reaffirm the inherent right to life of all persons with disabilities, shall take all necessary measures to ensure its effective enjoyment by them, and shall ensure that disability, or perceived quality of life, shall not serve as a basis for infringement of the right to life." [19]

These international political statements and agreements are also reflected in the resolution of the International Federation for Spina Bifida and Hydrocephalus (IF) as formulated at the 12th International Conference ("The Right to be Different") for Hydrocephalus and Spina Bifida in Toulouse [34]:

1. People with spina bifida and hydrocephalus can live a full life with equal value to that of any other citizen and they should not be seen as a medical condition. Their views should be sought and heard by governments and 
health professionals, who should acknowledge the right of people with spina bifida and hydrocephalus to speak for themselves.

2. People with disabilities have the right to aim for lives as rewarding as those of their peers who have what is regarded as a normal life. Supportive systems must be in place when they are needed.

3. Experience over the past 30 years has improved considerably the medical outcome and the quality of life of people with spina bifida and hydrocephalus.

4. Most adults with spina bifida underline that their quality of life is not automatically - and should not be given as - a reason for abortion [34].

As a recognition of the importance of non-discrimination on the basis of disability (that is to say, present as well as expected disability) or (expected) quality of life in deciding whether or not a newborn child with, e.g., spina bifida should be treated or whether or not it is justified to deliberately terminate such a child's life, Dorscheidt (2006) recommends to involve the legal concept of 'objective justification' in the medical-decision making process. By

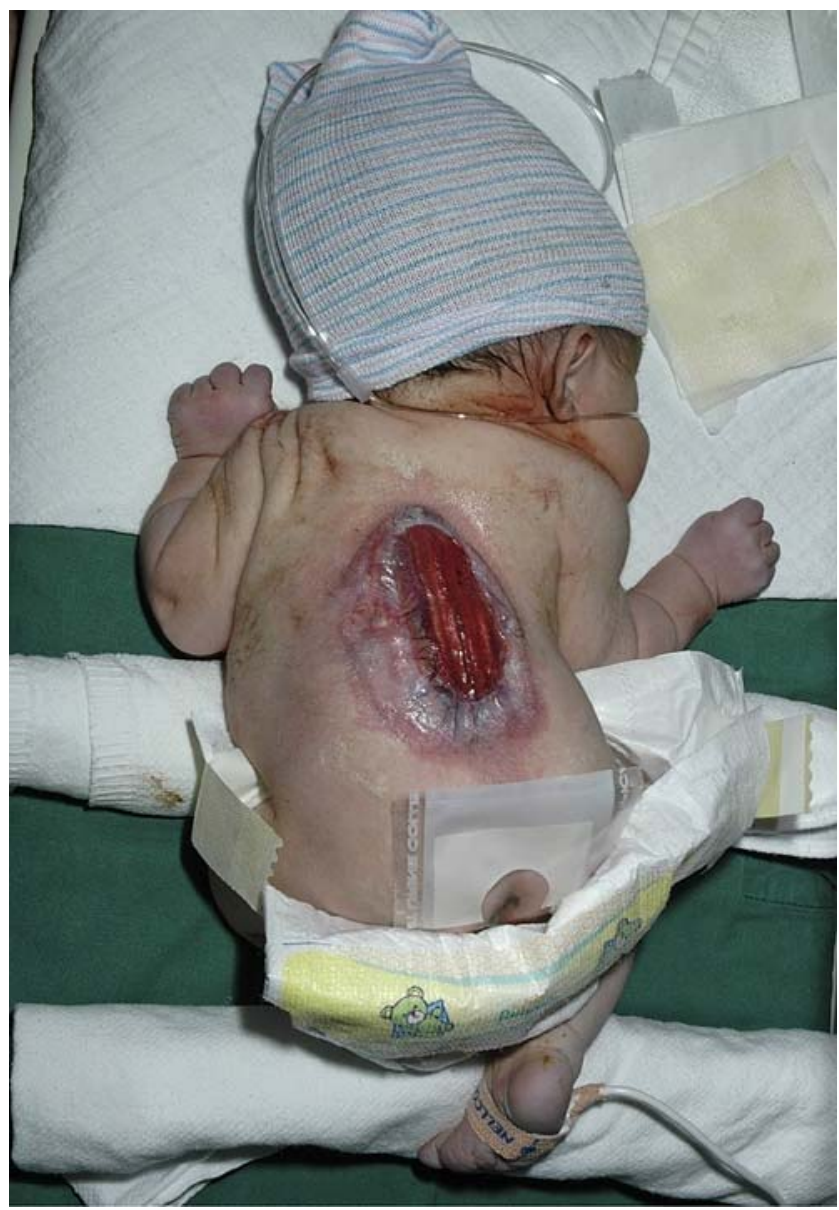

Fig. 1 Photograph of the newborn, showing the extensive MMC, extending from $+/-$ the 4 th thoracic vertebra till the midlumbar region

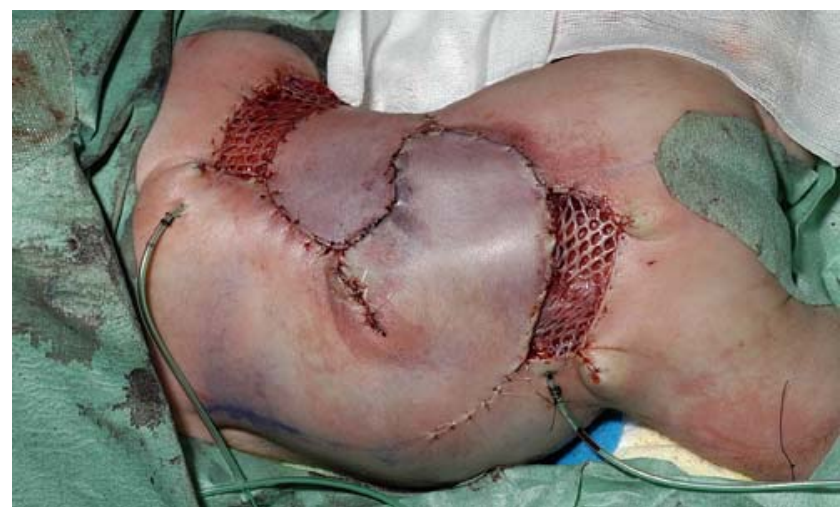

Fig. 2 Photograph at the end of the surgical procedure. The MMC was closed by making use of extensive rotational flaps together with free skin grafting

using a particular questionnaire, the physician in charge may take advantage of this concept when considering (and deliberating on) how to act properly and professionally. Through this, the physician can ensure the disabled newborn child's rightful claim to equal protection of its right to life and its right to health(care). Doing so would offer possibilities to replace the usual doctor-centered approach of decision making by a more patient-centered approach as well.

To summarize from another perspective: "Prominent theories of justice emphasize equality of opportunity for human experience and development; if society has an obligation to provide citizens this very broad equality of opportunity, then it has an obligation to shoulder the burden of care associated with citizens who have spina bifida" [11].

\section{Palliative care for untreated newborns with MMC}

When a newborn with spina bifida is not treated, discomfort can be expected in the nearby future caused by the lesion itself (e.g., by becoming infected), by a subsequent meningitis/ventriculitis, or by raised intracranial pressure caused by an untreated hydrocephalus. Therefore, the decision not to treat should always be accompanied by offering proper palliative care. It is becoming increasingly evident that, taken modern palliative techniques in newborns seriously, pain and discomfort can always be dealt with in an adequate way [43, 57]. In their article "Strong opioids in pediatric palliative medicine" Hain et al. (2005) also stated that "clinical evidence is accumulating that strong opioids can be used safely and effectively; they should be used as part of a rational approach to the management of pain" [28]. This use of strong pain killers is also highlighted in the recent Oxford Textbook of Palliative Care for Children [16]. In the highly unlikely event of 


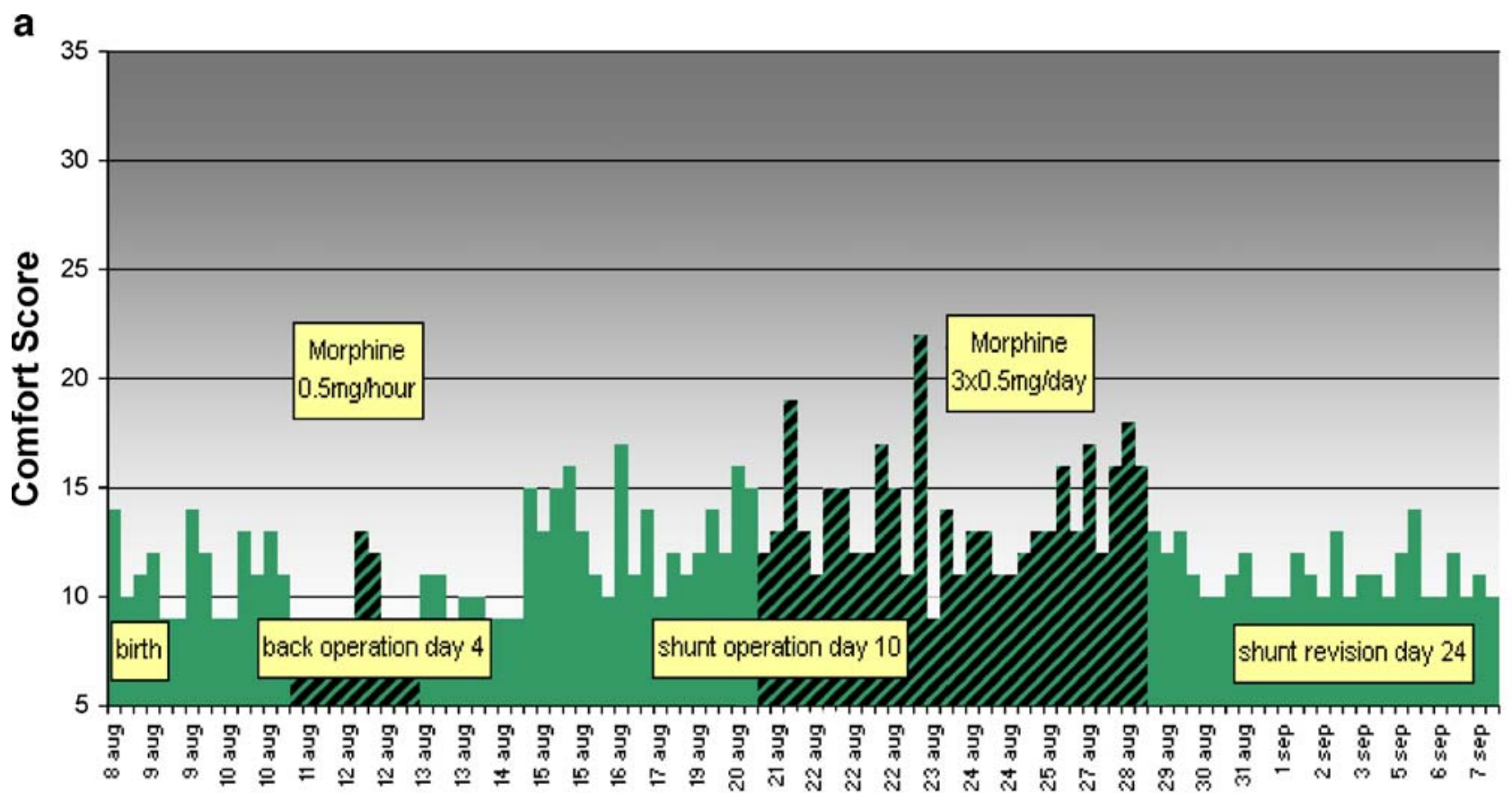

b

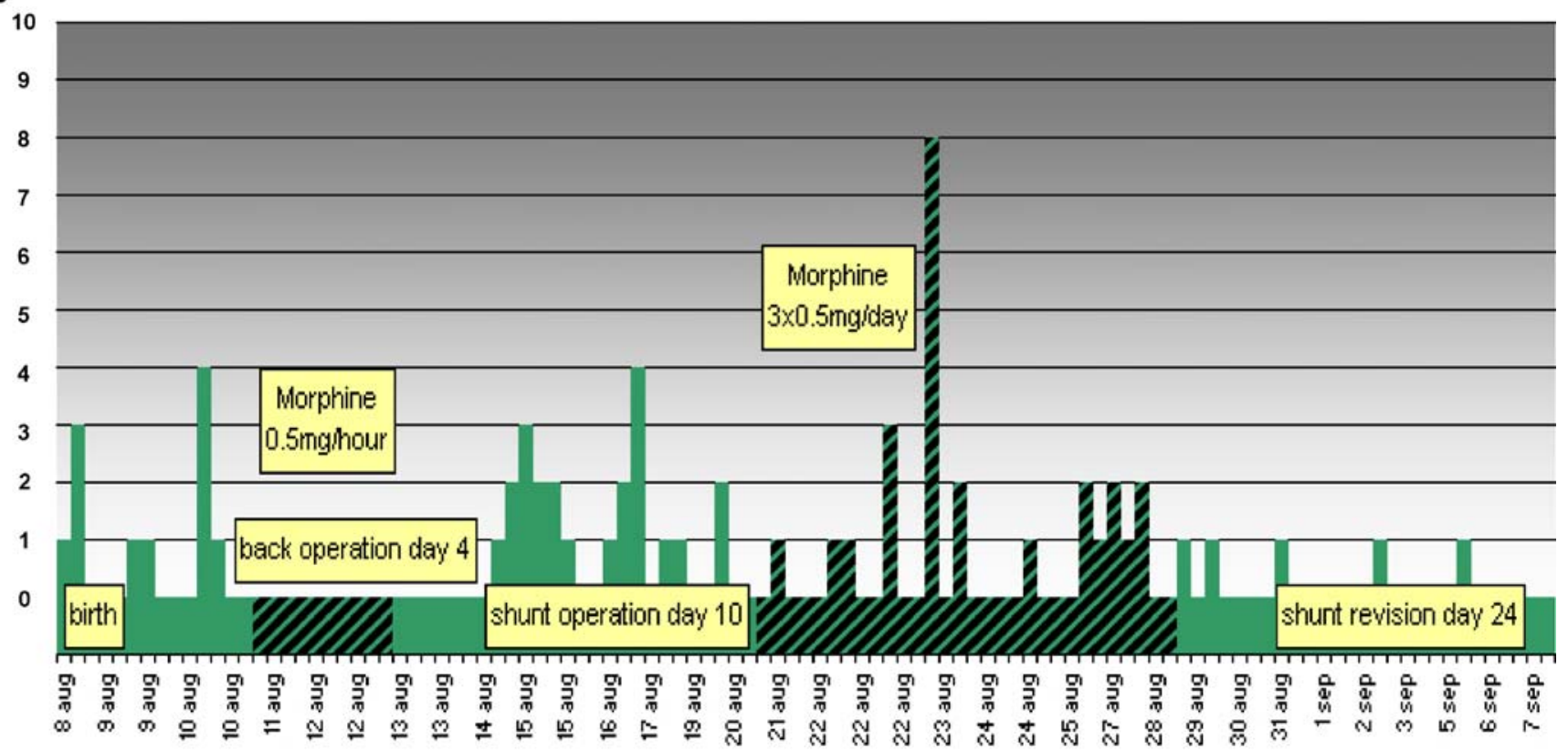

\section{VAS Score}

Fig. 3 a Comfort scores during the first month of life ( $\min =5$ : no discomfort; $\max =35$ : extreme discomfort). Green bars: only paracetamol (intermittently) being used. Green/black bars: low-dose morphine together with paracetamol being used. b The same as a, but now with the VAS ( $\min =0$ : no pain; $\max =10$ : most severe pain) Note: The combination of a Comfort score of at least 17 and a VAS of

insufficient effect of modern pain medication, terminal palliative sedation should be the next step in the palliative approach [16]. With palliative sedation, the possible experience itself of discomfort can always be dealt with adequately. In the "Consensus guidelines on sedation and at least 4 indicates that the well-being of the newborn is in jeopardy. In such a situation, the attending nurse is expected to determine the cause of the discomfort and to take adequate measures (changing a full nappy, feeding a hungry child, emptying a full bladder, giving adequate painkillers if appropriate, etc.) to secure the child's wellbeing

analgesia in critically ill children" by Playfor et al. (2006) in Intensive Care Medicine, some 20 guidelines are mentioned by which pain and discomfort in critically ill children can be treated in an efficient way; life termination not being mentioned at all [56]. 


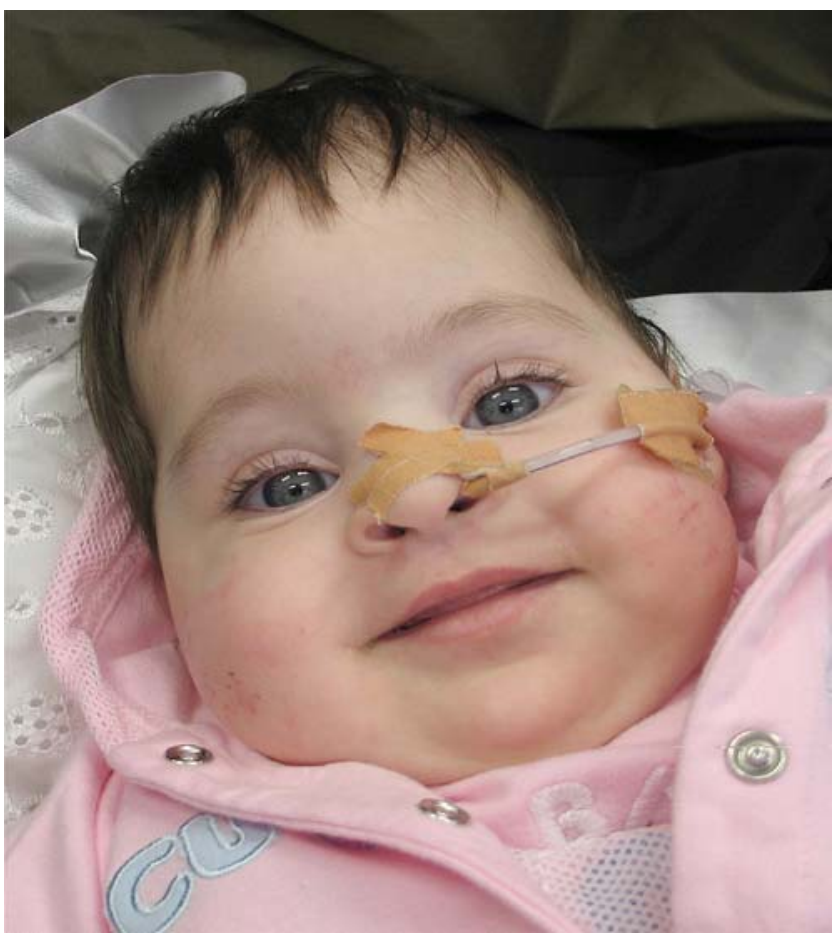

Fig. 4 The same child at 7 months old; fixating and following with the eyes, vocalizing, normal movements of the arms, moving both legs vigorously (perhaps nonvoluntary), still being partially fed by a nasogastric tube

When it is decided that surgical treatment is not a feasible option in a newborn with spina bifida, it is regarded by some to be an act of 'mercy' to terminate the life of the newborn [72]. This notion, however, is a misconception: they are not terminally ill because of the MMC and/or hydrocephalus per se; they are 'terminally ill' because of the decision not to treat their congenital malformations. The needs of these untreated newborns, however, are still the same as the needs of all newborns: proper care, feeding, comfort, respect and love; till death (and apparently not death itself). The 'need' for life termination in these patients can only be regarded as an indication of insufficient palliative care. Life termination as an act of mercy can only be applied to hopeless situations that can occur, e.g., on battlegrounds or in mountaineering, when there are no proper means indeed to alleviate real unbearable suffering. This is obviously not the case in a modern equipped hospital (at least, it should not be) with experience in palliative care and pain management.

This is all confirmed in the paper of Sauer in 2001, "Ethical dilemmas in neonatology: recommendations of the Ethics Working Group of the CESP (Confederation of European Specialists in Pediatrics)" in the European Journal of Pediatrics [60]. In this paper, some ethical principles, applicable to every newborn, are being formulated, like: "decisions to withhold or withdraw treatment should always be accompanied by optimal palliative therapy and dignified and comforting care" and "every form of intentional killing should be rejected in paediatrics" [60]. This is followed by: "However, giving medication to relieve suffering in hopeless situations which may, as a side effect, accelerate death, can be justified".

To date, it is not clear why these recommendations should not hold for cases of untreated spina bifida and hydrocephalus in the Netherlands and why the Dutch Association of Paediatrics does not adopt these recommendations.

\section{Illustrative case}

After an uneventful pregnancy, a full-term female child was delivered spontaneously, Apgar scores being 4 and 5 . Physical examination revealed a huge MMC at high thoracic level (Fig. 1), a very large head with a large but soft fontanel, a marked deformation of the thorax with scoliosis, and clubfeet. After counseling the parents, they persisted in their wish to treat the child, if this probably could save her life. The MMC team decided to respect the parents will and on day 3 the back lesion was closed by the neurosurgeon in collaboration with the plastic surgeon, making use of extensive rotational flaps together with free skin grafting (Fig. 2). Shunt placement could be postponed till day 9; a medium pressure valve being used. Because postoperatively the fontanel did not soften adequately, 2 weeks later the medium pressure valve was changed in a low-pressure valve, now with satisfying clinical results.

All period long, from birth till 1 week after the shunt revision, the well-being of the baby was estimated by making use of the Comfort score and the VAS and also medication used for treatment of pain or discomfort (paracetamol and morphine) was recorded (Fig. 3a,b).

Studying these data and particularly the amount of medication needed, several conclusions can be made:

1. When untreated (the first 3 days), the child was not discomfortable.

2. Closing of the back lesion, in this case certainly a major procedure, did not contribute significantly (and only temporarily) to more discomfort. In other words, closing of the open spine can be qualified as a proportional treatment modality.

3. The same holds true for placing a ventricular shunt.

4. Treating an active hydrocephalus adequately contributes to the well-being of the patient.

5. In 1 month's time, this active treatment resulted in a stable situation of overall well-being in this patient.

6. Only paracetamol and low-dose morphine were necessary in the treatment of actual discomfort.

In summary, this case not only demonstrates that there is no such thing as 'suffering' in these newborns, but also 


\section{a}

\section{COMFORT SCORE}

220 monitoring moments $<18(96.5 \%)$

8 monitoring moments $>17(3.5 \%)$

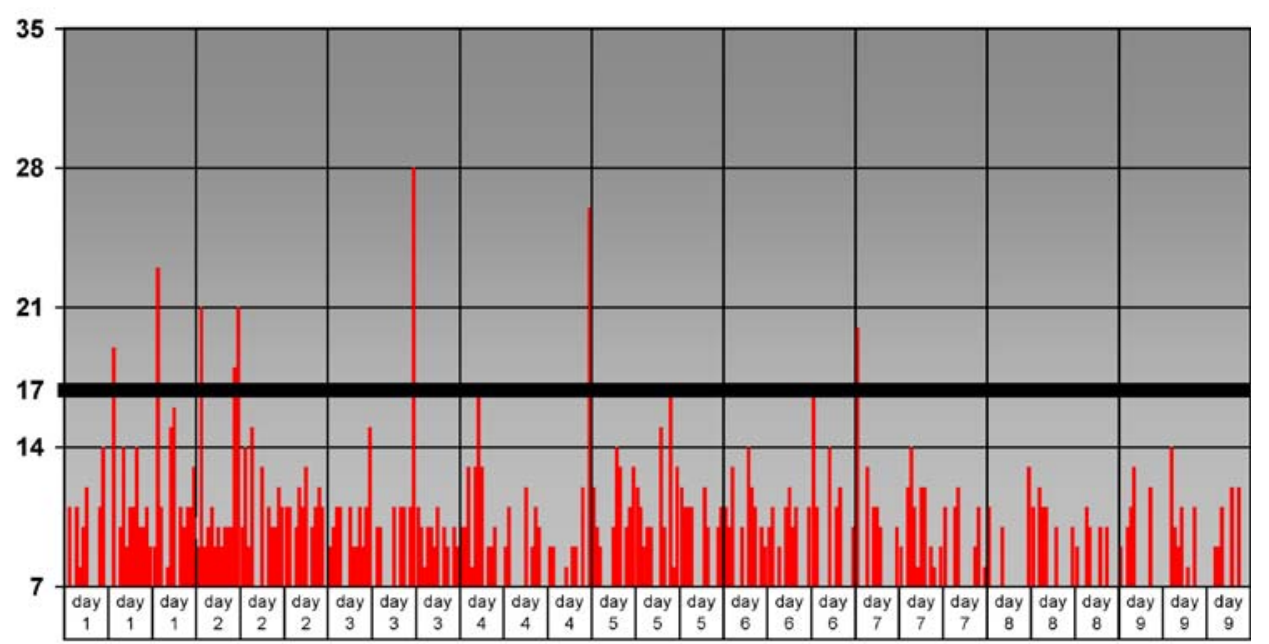

b

VAS SCORE
196 monitoring moments ( $92.5 \%)$
score 0 (no pain)
13 monitoring moments $(6.1 \%)$
score $0.5-5$
3 monitoring moments $(1.4 \%)$
score $>5$

9 day monitoring period
for each patient
(monitoring $3 \times$ per day)

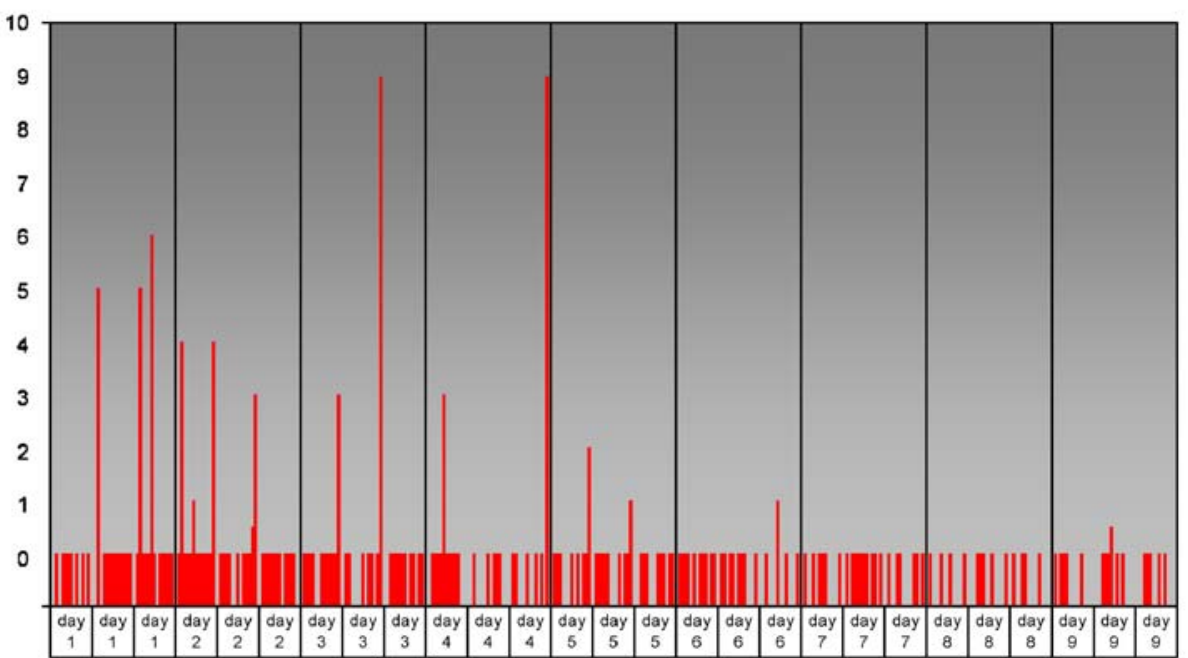

Fig. 5 a and b Preliminary results of the Rotterdam Prospective Study on Discomfort in Newborns with MMC $(n=13)$

the incorrectness of the statement of Verhagen et al. (2005a) [73] that "the suffering of these newborns cannot be alleviated by any means in a proper medical way" (Fig. 4). The overall impression of this case is in accordance with the preliminary results of the Rotterdam Prospective Study on Discomfort in Newborns with MMC: there is no "acutely unbearable suffering" in these newborns (Figs. 5a,b)

Although in an interview Verhagen himself reported that "all 22 cases had a lesion of the most severe form, at level of the neck" [78], in their published articles Verhagen et al. [73_76] do not quantify the level of the lesion. However, it seems very unlikely that his statement is correct or that the levels of lesion in these 22 cases are of the same level and/ or magnitude as in the case described.

\section{Synthesis and conclusion}

There is no evidence that newborns with MMC and hydrocephalus do either 'suffer' unbearably or hopelessly and certainly not without the prospect to relieve this suffering by standard care. 'Suffering' itself is a nonconclusive, and in newborns, inapplicable denominator that should not be used anymore in this debate. Although they will in their future life be confronted with handicaps, sometimes very severe, their future prospects and their actual experienced quality of life cannot be predicted with such certainty at birth that their lives can be regarded as hopeless or meaningless ('quality of life judgments' as such being unacceptable in this decision making). Possible discomfort in these newborns can easily be treated in a 
straightforward way by active treatment (closure of the defect and shunting the hydrocephalus) and, when necessary, by the use of a professional pain/symptom protocol.

The decision not to treat such a newborn, when based on expected handicaps, possibly violates the 'non-discrimination' principle (Dorscheidt, 2006). When not being treated, they are not terminally ill because of the MMC and/or hydrocephalus per se; they are 'terminally ill' because of this nontreatment decision. Not being terminally ill, it is not 'humane' or 'merciful' to terminate their life, this also being not in accordance with international legislation and international medical recommendations.

When untreated and when it is the intention to alleviate actual discomfort (this question of intent being crucial to a moral and legal analysis of end-of-life decisions including active termination of life), this can always be achieved in an effective way by using one of the widely accepted palliative protocols. Such a child can and should be cared for in a respectful and dignified way, providing all its actual needs (which apparently is not death itself). This being the case, there is no indication whatsoever for the deliberate termination of the life of children born with MMC.

While Verhagen et al. $(2005,2006)$ must be credited for bringing the discussion about deliberate termination of newborns in the open, to date, there does not seem to be much in their qualifications that can be quantified properly, especially not in cases of MMC, which is prone to quality of life judgments (and thereby neglecting the needs and rights of the newborn). To date, the Groningen protocol, therefore, cannot be regarded as very useful. Being a tool, it seems to have been changed in a means in itself. To gain more usefulness, at least it has to be extended in a way as proposed by Dorscheidt (2006), by adding charts such as the Comfort Score and the VAS and by adding palliative medication charts. Thus, it should be changed from a doctor-centered protocol to a patient-centered protocol.

To throw more light on these end-of-life decisions, Verhagen et al. should consider to extend their retrospective study, focusing on the medical aspects of the 22 cases. Thus, it must be possible to get a basic understanding of the extent of the malformations themselves, of possible comorbidities, whether or not quality of life judgments were made, how 'unbearable suffering' was ascertained, how palliative care was offered, and why this failed. Such a study would contribute significantly to the open discussion they propagate. Verhagen is undoubtedly correct indeed in his appeal: "It's time to be honest about the unbearable suffering endured by newborns with no hope of a future". [71]

Finally, to date it remains unclear on what grounds the Dutch Association of Paediatrics has adopted the Groningen protocol and why international legislation, international human rights instruments, and international medical rec- ommendations appear not to hold for the Netherlands, especially not in newborns with MMC.

Acknowledgements The author is much indebted to E.J.O. Kompanje, clinical ethicist, for his generous and stimulating help in preparing this article.

\section{References}

1. Amacher AL, Wellington J (1984) Infantile hydrocephalus: longterm results of surgical therapy. Child Brain 11:217-229

2. Anonymous (1979) Non-treatment of defective newborn babies. Lancet 1123-1124

3. Barf HA (2003) Cognitive status of young adults with spina bifida. Dev Med Child Neurol 45:813-820

4. Barf HA, Verhoef M, Post MWM, Jennekens-Schinkel A, Gooskens RHJM, Mullaart RA, Prevo AJH (2004) Educational career and predictors of type of education in young adults with spina bifida. Int J Rehabil Res 27:45-52

5. Beeker TW, Scheers MM, Faber JAJ, Tulleken CAF (2006) Prediction of independence and intelligence at birth in meningomyelocele. Child's Nerv Syst 22(1):33-37

6. Beijk MM (1998) Ondraaglijk lijden. Med Contact 24:825-827 (in Dutch)

7. Black PM (1979) Selective treatment of infants with myelomeningocele. Neurosurgery 5:334-338

8. Bondi JD, Gries D, Faucette K (2006) Neonatal Euthanasia? Pediatrics 117(3):983

9. Bowman RM, McLone DG, Grant JA, Tomita T, Ito JA (2001) Spina bifida outcome: a 25 -year prospective. Pediatr Neurosurg 34:114-120

10. Bruner J, Tulipan N (2004) Tell the truth about spina bifida. Ultrasound Obstet Gynecol 24:595-596

11. Chervenak FA, McCullough LB, Arabin B (2006) Why the Groningen Protocol should be rejected. Hastings Center Report, Sept-Oct 2006, pp. 30-34

12. Clancy CA, McGrath PJ, Oddson BE (2005) Pain in children and adolescents with spina bifida. Dev Med Child Neurol 47:27-34

13. Cornel MC, Leurquin P, de Walle HEK, Staal-Schreinemakers AL, Beekhuis JR (1997) Epidemiologie van prenatale diagnostiek en selectieve zwangerschapsafbreking vanwege foetale neuralebuisdefecten in Nederland in vergelijking met andere Europese landen. Ned Tijdschr Geneeskd 141:2239-2244 (in Dutch)

14. Cragan JD, Roberts HE, Khoury MJ, Kirby RS, Shaw GM, Velie EM, Merz RD, Forrester MB, Williamson RA, Krishnamuriti DS, Stevenson RE, Dean JH (1995) Surveillance for anencephaly and spina bifida and the impact of prenatal diagnosis-United States, 1985-1994. MMWR CDC Surveillance Summaries 44:1-23

15. Crul BVM, Legemaate J (2007) Euthanasie en coma. Med Contact 62(10):436 (in Dutch)

16. Davies D, de Vlaming D (2006) Symptom control at the end-oflife. Oxford Textbook of Palliative Care for Children, pp. 502505,507

17. Delight E, Goodall J (1988) Babies with spina bifida treated without surgery: parents views on home versus hospital care. BMJ 297:1230-1233

18. Delight E, Goodall J (1990) Love and loss. Conversations with parents of babies with spina bifida managed without surgery, 1971-1981. Dev Med Child Neur 32(Suppl 61):1-58

19. Dorscheidt JHHM (2006) Levensbeëindiging bij gehandicapte pasgeborenen. Strijdig met het non-discriminatiebeginsel? (Med- 
ical termination of disabled neonatal life. Compatible with the principle of non-discrimination?) Thesis, State-University Groningen, Sdu: Den Haag, 2006. (in Dutch)

20. Edwards RJ, Witchell C, Pople IK (2003) Chronic headaches in adults with spina bifida and associated hydrocephalus. Eur J Pediatr Surg 13:S13-S17

21. Feudtner C (2005) Control of suffering on the slippery slope of care. Lancet 365(9467):1284-1286

22. Frazier CH (1935) Surgery of the Spine and Spinal Cord. Appleton \& Co., NY and London, pp. $303 \mathrm{ff}$

23. Freeman JM (1984) Early management and decision making for the treatment of myelomeningocele: a critique. Pediatrics 73: 564-566

24. Freeman JM (1987) Making decisions for the severely handicapped newborn. J Health Polit Policy Law 11:285-294

25. Freeman JM (1998) Changing ethical issues in the treatment of spina bifida: a personal odyssey. Ment Retard Dev Disabil Res Rev 4:302-307

26. Griffiths J, Bood A, Weyers H (1998) Euthanasia and law in the Netherlands. Amsterdam University press, Amsterdam

27. Gross RH, Cox A, Tatyrek R, Pollay M, Barnes WA (1983) Early management and decision making for the treatment of myelomenigocele. Pediatrics 72:450-458

28. Hain RDW, Miser A, Devins M, Wallace WHB (2005) Strong opioids in pediatric palliative medicine. Pediatric Drugs 7(1):1-9

29. Hamburg F (2005) Een computermodel voor het ondersteunen van euthanasiebeslissingen. Thesis, University of Leiden (in Dutch)

30. Hertogh CMPM (1988) Ethische weging van dilemma's ontstaan door selectieve behandeling van de pasgeborene met spina bifida. Ned Tijdschr Geneeskd 132(45):2070-2073 (in Dutch)

31. Hetherington R, Dennis M, Barnes M, Drakes J, Gentili F (2006) Functional outcome in young adults with spina bifida and hydrocephalus. Child's Nerv Syst 22:117-124

32. Hunt GM, Oakeshott P (2003) Outcome in people with open spina bifida at age 35: prospective community based cohort study. BMJ 326:1365-1366

33. Iddon J, Morgan D, Loveday C, Sahakian B, Pickard J (2004) Neuropsychological profile of young adults with spina bifida with or without hydrocephalus. J Neurol Neurosurg Psychiatry 75: $1112-1118$

34. 'The Right to be Different': http://www.ifglobal.org/pregnancy. asp?lang $=1 \&$ main $=8 \&$ sub $=3$

35. Jong de T, van Lindert E, Kompanje E, Rotteveel J (2006) Laten sterven of doen sterven. Med Contact 61(16):669-671 (in Dutch)

36. Jotkowitz AB, Glick S (2006) The Groningen Protocol: another perspective. J Med Ethics 32:157-158

37. Klotzko AJ (1997) What kind of life? What kind of death? An interview with Dr. Henk Prins. Bioethics 11:24-42

38. Kompanje EJO, de Jong THR, Arts WFM, Rotteveel JJ (2005) Problematische basis voor 'uitzichtloos en ondraaglijk lijden' als criterium voor actieve levensbeëindiging bij pasgeborenen met spina bifida. Ned Tijdschr Geneeskd 149(37):2067-2069 (in Dutch)

39. Laane HM (2005a) Actieve levensbeëindiging bij pasgeborenen in Nederland; analyse van alle 22 meldingen uit 1997/'04. Ned Tijdschr Geneeskd 149(20):1134 (in Dutch)

40. Laane HM (2005b) Actieve levensbeëindiging bij pasgeborenen in Nederland; analyse van alle 22 meldingen uit 1997/'04. Ned Tijdschr Geneeskd, 149(49):2762-2733 (in Dutch)

41. de Lange SA (1974a) Een enquete over de behandeling van pasgeborenen met spina bifida aperta. Med Contact 29:887-890 (in Dutch)

42. Lange de SA (1974b) Selection for treatment of patients with spina bifida aperta. Proceedings of the Society for research into hydrocephalus and spina bifida Gothenburg 27-30, 12-15 June 1974

43. Lingen van $R$ (2000) Pain assessment and analgesia in the newborn: an integrated approach. Thesis, University of Rotterdam
44. Lorber J (1971) Results of treatment of myelomeningocele: an analysis of treatment of 524 unselected cases with special reference to possible selection for treatment. Dev Med Child Neurol 13:279-303

45. Manninen BA (2006a) A case for justified non-voluntary active euthanasia: exploring the ethics of the Groningen Protocol. J Med Ethics 32:643-651

46. Manninen BA (2006b) Regarding the Groningen Protocol. J Med Ethics 23, November 2006

47. Mataró M, Junqué C, Poca M, Sahuquillo J (2001) Neuropsychological Findings in Congenital and Acquired Childhood Hydrocephalus. Neuropsychol Rev 11(4):169-178

48. McLone D (1982) Results of treatment of children born with a myelomeningocele. Clin Neurosurg 30:407-412

49. McLone D (1985) Treatment of myelomeningocele: arguments against selection. Clin Neurosurg 33:359-370

50. Mitchell LE, Adzick NS, Melchionne J, Pasquariello PS, Sutton LN, Whitehead AS (2004) Spina bifida. Lancet 364:1885-1895

51. Newman J (1987) Making decisions for the severely handicapped newborn. J Health Polit Policy Law 11:294-297

52. Oakeshott P, Hunt GM (2003) Long-term outcome in open spina bifida. Br J Gen Pract 53:632-636

53. Olde Scholtenhuis MAG, Cohen-Overbeek TE, Offringa M, Barth PG, Stoutenbeek P, Gooskens RH, Wladimiroff JW, Bilardo CM (2003) Audit of prenatal and postnatal diagnosis of isolated open spina bifida in three university hospitals in The Netherlands. Ultrasound Obstet Gynecol 21:48-52

54. Padua L, Rendeli C, Rabine A, Firardi E, Tonali P, Salvaggio E (2002) Health-related quality of life and disability in young patients with spina bifida. Arch Phys Med Rehabil 83:13841388

55. Pit-ten Cate IM, Kennedy C, Stevenson J (2002) Disability and quality of life in spina bifida and hydrocephalus. Dev Med Child Neurol 44:317-322

56. Playfor S, Jenkins I, Boyles C, Choonara I, Davies G, Haywood T, Hinson G, Mayer A, Morton N, Ralph T, Wolf A (2006) United Kingdom Paediatric Intensive Care Society Sedation Analgesia and Neuromuscular Blockade Working Group (2006). Consensus guidelines on sedation and analgesia in critically ill children. Intensive Care Med 32(8):1125-1136

57. Prins SA (2005) Under a watchful eye...New medication and monitoring of sedation and analgesia in pediatric intensive care. Thesis, University of Rotterdam

58. Rendeli C, Ausili E, Tabacco F, Caliandro P, Aprile I, Tonali P, Salvaggio E, Padua L (2005) Assessment of health status in children with spina bifida. Spinal Cord 1:1-6

59. Rotteveel JJ, Mullaart RA, Gabreels FJM, Van Overbeek JJ (1996) Actieve levensbeeindiging bij pasgeborenen met spina bifida? Ned Tijdschr Geneeskd 140:323-324 (in Dutch)

60. Sauer PJJ (2001) Ethical dilemmas in neonatology: recommendations of the Ethics Working Group of the CESP (Confederation of European Specialists in Paediatrics). Eur J Pediatr 160:364-368

61. Saugstad OD (2005) When newborn infants are bound to die. Acta Paediatr 1535-1537

62. Sawin KJ, Brei TJ, Buran CF, Fastenau PS (2002) Factors associated with quality of life in adolescents with spina bifida. $\mathrm{J}$ Holist Nurs 20:279-304

63. Sawyer SM, Roberts KV (1999) Sexual and reproductive health in young people with spina bifida. Dev Med Child Neurol 41:671675

64. Schoenmakers M (2003) Functional aspects of spina bifida in childhood. Thesis, University of Utrecht

65. Seller MJ (1990) Is antenatal selection for spina bifida possible? BMJ 251-252

66. Smith ED (1965) Spina bifida and the total care of spinal myelomeningocele. Charles C Thomas, Springfield 
67. Snow J, Prince M, Souheaver G, Ashcraft E, Stefans V, Edmonds J (1994) Neuropsychological patterns of adolescents and young adults with spina bifida. Arch Clin Neuropsychol 9(3):277-287

68. Steinbok P, Irvine PB, Cochrane DD, Irwin BJ (1992) Long-term outcome and complications of children born with meningomyelocele. Child's Nerv Syst 8:92-96

69. Sutton LN (1985) Myelomeningocele - the question of selection. Clin Neurosurg 33:371-381

70. Tuli S, Drake J, Lamberti-Pasculli M (2003) Long-term outcome of hydrocephalus management in myelomeningoceles. Child's Nerv Syst 19:286-291

71. UMCG (2004) Paediatricians call for nationwide protocol for the ending of life of unbearably and incureably suffering newborns. http://www.azg.nl/azg/nl/english/nieuws/45613?pathkey=6936

72. van de Vathorst S (2003) De dood als beste optie. Med Contact 58:1471-1473 (in Dutch)
73. Verhagen AAE, Sol JJ, Brouwer OF, Sauer PJ (2005a) Actieve levensbeeindiging bij pasgeborenen in Nederland; analyse van alle 22 meldingen uit 1997/'04. Ned Tijdschr Geneeskd 149:183-188 (in Dutch)

74. Verhagen AAE, Sol JJ, Brouwer OF, Sauer PJ (2005b) Ned Tijdschr Geneeskd, 149(20):1135 (in Dutch)

75. Verhagen A, Sauer P (2005c) End-of-life decisions in newborns: an approach from the Netherlands. Pediatrics 116:736-739

76. Verhagen E, Sauer PJJ (2005d) The Groningen Protocoleuthanasia in severely ill newborns. New Engl J Med 352:959962

77. Verhoef M (2005) Spina bifida: implications for functioning and health in young adults. Thesis, University of Utrecht

78. Visser de E (2005) Moord volgens protocol. Volkskrant 22 January 2005 (in Dutch)

79. Zachary RB (1977) Life with spina bifida. BMJ:1460-1462 